\title{
Effect of Rosemary Essential Oil on the Quality Characteristics of Chicken Nuggets
}

\author{
M. Sutha ${ }^{1 *}$, R. Selvaraj ${ }^{2}$, V.V. Kulkarni ${ }^{3}$, V. Chandirasekaran ${ }^{4}$, \\ S.C. Edwin ${ }^{5}$ and S. Malmarugan ${ }^{6}$ \\ ${ }^{1}$ Department of Livestock Products Technology (Meat Science), Veterinary College Research \\ Institute, Tirunelveli, Tamil Nadu, India \\ ${ }^{2}$ Veterinary University Training and Research Centre, Erode, Tamil Nadu, India \\ ${ }^{3}$ Veterinary College Research Institute, Namakkal, Tamil Nadu, India \\ ${ }^{4}$ Instructional Livestock Farm Complex, Veterinary College Research Institute, Namakkal, \\ Tamil Nadu, India \\ ${ }^{5}$ Instructional Livestock Farm Complex, Veterinary College Research Institute, Tirunelveli, \\ Tamil Nadu, India \\ ${ }^{6}$ Veterinary University Training and Research Centre, Nagerkoil, Tamil Nadu, India \\ *Corresponding author
}

\section{A B S T R A C T}

\begin{tabular}{|l|}
\hline K e y w or d s \\
$\begin{array}{l}\text { Essential oils, Roesemary, } \\
\text { Chicken nuggets, Physico- } \\
\text { chemical and Organoleptic } \\
\text { quality characteristics }\end{array}$ \\
\hline Article Info \\
\hline $\begin{array}{l}\text { Accepted: } \\
\text { 26 July 2018 } \\
\text { Available Online: } \\
\text { 10 August 2018 }\end{array}$ \\
\hline
\end{tabular}

\section{Introduction}

Poultry sector has emerged out as an organized, scientific and one of the faster growing sector of livestock economy. Globally, poultry meat has become a mass consumer product due to its cost competitiveness, nutritional quality, universal availability and absence of religious taboos
The study was envisaged to evaluate the effect of rosemary essential oil on physico chemical and organoleptic quality characteristics of chicken nuggets. No significant difference was observed in $\mathrm{pH}$, emulsion stability, product yield and shear force value; however significant difference was observed in DPPH scavenging activity at $(\mathrm{P}<0.01)$ level. The flavour $(6.79 \pm 0.12)$ and overall acceptability $(6.90 \pm 0.07)$ was also significantly higher for $0.10 \%$ of rosemary oil treated nuggets compared to control and other treated nuggets. However, no significant difference was observed in the sensory scores of chicken nuggets for appearance, spiciness, texture and juiciness. Hence, based on the results, it can be concluded from this study that $0.10 \%$ of rosemary essential incorporated chicken nuggets was successfully improved the functional and sensory quality. 
perishable products and easily become unfit for human consumption, possibly due to microbial growth, chemical changes and break down by endogenous enzymes. They also undergo rapid changes chiefly lipolysis and proteolysis leading to sensory deterioration and high risks of food borne pathogens (Casaburi et al., 2011). To solve these serious food safety problems, producers are seeking new and improved manufacturing practices to prevent microbiological contamination and lipid oxidation.

In recent years, consumers are increasingly focused on the use of natural products and natural substances, especially of plant origin rather than synthetic preservatives because of their potential toxicological effects (Naveena, et al., 2008).

Among the natural substances essential oils from spices are the most appropriate and promising substances, used in meat products to enhance its sensory and microbial quality. Essential oils are the volatile, natural, aromatic oily liquids extracted from plant materials, such as leaves, fruits, seeds and barks. They are characterized by a strong odour and are formed by plants as secondary metabolites (Burt, 2004).

Among the essential oils, rosemary (Rosmarinus officinalis) oil is widely used for preservation by the food industry. Rosemary, a member of the Lamiaceae family is a herbal spice is used in cuisines not only to improve or modify the flavour of food, but also to prevent its deterioration because of its antimicrobial and antioxidant activities (Fernandez et al., 2005). Many authors have demonstrated the antioxidant and antimicrobial effect of rosemary essential oil (REO) as a natural antioxidant that prevented lipid oxidation (Balentine et al., 2006; Hussain et al., 2010) and as antimicrobial agent to inhibit the growth of various foodborne pathogens in vitro (Hammer et al., 1999). However, its effectiveness when applied to meat products has not been extensively investigated. Hence, the study is envisaged with the objective to investigate the effect of rosemary essential oil on the physico-chemical and sensory characteristics of chicken nuggets.

\section{Materials and Methods}

\section{Preparation of chicken nuggets}

Dressed broiler carcasses were purchased from the retail outlets and the carcass was hygienically deboned and trimmed off all visible adipose and connective tissues. The deboned meat was minced through an 8-mm plate using a meat mincer. The certified food grade rosemary essential oils purchased from M/s. Akay Flavour and Aromatics Pvt. Limited, Kochi, were used to incorporate to chicken nuggets at different levels. The three levels $(0.05 \%, 0.10 \%$ and $0.25 \%)$ of incorporation of rosemary essential oil in chicken nuggets was standardized. The three levels of incorporation of rosemary essential oil in chicken nuggets was optimized after several preliminary trials. The nuggets were prepared by blending of minced meat with salt and other ingredients in the bowl chopper as per the requirements of each treatment. The mixing was continued till a homogenous viscous emulsion was formed. The composition of spice mix and the standardized formulations used for nuggets preparation are presented in Table 1.

For the preparation of nuggets, about 350gm of emulsion was tightly filled in stainless steel mould, which was steam cooked for 40-45 minutes to reach the internal temperature of $80 \pm 2^{\circ} \mathrm{C}$. After cooking, the mould was removed from steam cooker and cooled at room temperature. Nuggets were prepared by cutting meat block into small cubes with the help of meat slicer and evaluated immediately. 


\section{Physico-chemical analysis}

\section{Determination of $\mathbf{p H}$}

A method of Trout et al., (1992) was followed for measuring $\mathrm{pH}$ of the emulsion and product, $10 \mathrm{gm}$ of sample was homogenized with $50 \mathrm{ml}$ of distilled water by using tissue homogenizer (Polytron PT 3100, Switzerland) for about 1 minute.

The $\mathrm{pH}$ of the homogenate was recorded by immersing combined glass electrode and temperature probe of the digital $\mathrm{pH}$ meter (Model 361, Systronics, India).

\section{Emulsion stability}

The emulsion stability of raw emulsion was determined by the method of Baliga and Madaiah (1971) as modified by Kondiah et al., (1985) and emulsion stability was calculated as follows

Emulsion stability $(\%)=\frac{\text { Weight after heating }}{\text { Raw emulsion weight }} \times 100$

\section{Product yield}

Weight of raw and cooked chicken nuggets were recorded. The percent cooking yield for each chicken nuggets was calculated as follow.

Product yield $(\%)=\frac{\text { Weight of cooked chicken nuggets }}{\text { Raw emulsion weight }} \times 100$

\section{Shear force value}

Shear force value was determined as per the method described by Berry and Stiffler (1981).

It is measured as force required for shearing one $\mathrm{cm}$ square $\left(1 \mathrm{~cm}^{2}\right)$ block on Warner Bratzler shear press and expressed in $\mathrm{kg} / \mathrm{cm}^{2}$

\section{DPPH radical scavenging activity}

The ability to scavenge 1, 1- diphenyl - $2-$ picrylhydrazyl (DPPH) radical by essential oils and chicken nuggets was determined by the procedure of Wu et.al (2003) with slight modifications. The concentration of essential oils used and chicken nuggets were taken in different test tubes. The volume was adjusted to $100 \mu \mathrm{l}$ by adding $95 \%$ ethanol as diluents. From that solution, $0.1 \mathrm{ml}$ was taken, mixed with $5 \mathrm{ml}$ of $0.1 \mathrm{mM}$ DPPH solution. The tubes were allowed to stand at $27^{\circ} \mathrm{C}$ for 30 minutes. The control was prepared as above without any essential oil and ethanol was used for the baseline correction. Changes in the absorbance of the samples were measured at $517 \mathrm{~nm}$ using a BECKMAN DU-640 UV-VIS spectrophotometer. DPPH radical scavenging activity was expressed as the inhibition percentage and was calculated using the following formula

DPPH scavenging activity $(\%)=\frac{A c-A s}{A c} \times 100$

Ac- Absorbance value of Control

As- Absorbance value of Sample

\section{Sensory analysis}

Experienced sensory panel consisting of meat scientists and students of the division evaluated the chicken nuggets for appearance, flavour, spiciness, texture, juiciness and overall palatability using 8 point descriptive scale (Keeton, 1983), where 8 denoted extremely acceptable, 1 denoted less acceptable. The sensory evaluation was done in environmentally controlled $\left(20 \pm 2^{\circ} \mathrm{C}\right)$ sensory evaluation laboratory with facility of individual booth for each panellist.

\section{Statistical analysis}

The each experiment was replicated at least six times and the data generated was analysed 
using standard statistical procedures (Snedecor and Cochran, 1994). ANOVA was used to determine significant differences $(\mathrm{P}<0.05)$ and highly significant $(\mathrm{P}<0.01)$ differences among means for the different treatments.

\section{Results and Discussion}

The objective of the study was to optimize the level of incorporation and evaluate the effect of three levels of rosemary added quality characteristics of chicken nuggets. The incorporation of rosemary in chicken nuggets may improve the quality characteristics of chicken nuggets. The detail of quality characteristics of chicken nuggets are presented in Table 2.

\section{pH}

No significant difference was observed in $\mathrm{pH}$ values in between control and essential incorporated chicken nuggets. However, slight numerically higher $\mathrm{pH}$ was observed for essential incorporated chicken nuggets.

The findings of this study were similar to the report of Seydim et al., (2006) noticed no change in $\mathrm{pH}$ between the rosemary oleoresin treated ostrich meat patties and the control patties. Darwish et al., (2012) also observed no significant change in $\mathrm{pH}$ in chicken burger formulated with rosemary extract and recommended incorporation of rosemary at $1 \%$ level. Moreover, slightly higher $\mathrm{pH}$ was observed in cooked samples, which would be due to denaturation of proteins and thus release of free amino groups, especially free $\mathrm{SH}$ groups that occurred at higher temperature (Lawrie, 1998).

\section{Emulsion stability}

The emulsion stability of chicken nuggets increased with increased level of incorporation of rosemary oil upto $0.1 \%$ concentration and at this level, higher value was observed when compared to $0.25 \%$ level. However, there was no significant difference between treated nuggets and control.

\section{Product yield}

No significant difference was observed in cooking yields of the control and essential incorporated chicken nuggets. Rosemary oil with $0.10 \%$ level of incorporation recorded higher value for product yield compared to other two treatments.

The increase in cooking yield of treated nuggets over the control could be attributed to the higher moisture retention during cooking. Similar finding was reported by Huber et al., (2002) in chicken sausages.

\section{Shear force value}

Shear force value of treated nuggets decreased numerically with increase in the inclusion levels of rosemary oil though not statistically significant. The shear force value of control was higher than all treatments. The result was in coincidence to Kanimozhi, 2014 who observed significant decrease in SFV in rosemary extract incorporated chicken nuggets.

\section{DPPH radical scavenging activity}

The DPPH scavenging activity of Rosemary essential oil was observed to be significantly $(\mathrm{P}<0.01) \quad$ increasing with increasing concentrations, highest value being observed in $0.25 \%$. The antioxidant activity of rosemary extracts has been primarily related to two phenolic diterpenenes: carnosic acid and carnosol (Frankel et al., 1996). The results of the DPPH scavenging activity of rosemary oil in the product revealed significant difference between treated and control nuggets but statistically comparable between treatments. 
Table.1 The spice mix and chicken nugget formulation used for preparation of chicken nuggets

Spice mix formulation

\begin{tabular}{|l|l|l|}
\hline Sl. No. & Ingredients & Percentage $(\mathbf{W} / \mathbf{W})$ \\
\hline 1. & Coriander & 40 \\
\hline 2. & Cumin seeds & 6 \\
\hline 3. & Fennel seeds & 10 \\
\hline 4. & Black pepper & 10 \\
\hline 5. & Poppy seeds & 2 \\
\hline 6. & Cinnamon & 1 \\
\hline 7. & Cloves & 2.0 \\
\hline 8. & Cardamon & 0.5 \\
\hline 9. & Nutmeg & 0.5 \\
\hline 10. & Star anise & 0.1 \\
\hline 11. & Bay leaf & 0.4 \\
\hline 12. & Turmeric & 1.0 \\
\hline 13. & Red chilly & 20 \\
\hline 14. & Mace & 0.5 \\
\hline 15. & Dried ginger & 6.0 \\
\hline & & 100 \\
\hline
\end{tabular}

Chicken nugget formulation

\begin{tabular}{|l|l|}
\hline Ingredients & Amount (g) \\
\hline Lean meat & 1000 \\
\hline Vegetable oil (sunflower oil) & 50 \\
\hline Salt & 20 \\
\hline Ginger & 25 \\
\hline Garlic & 25 \\
\hline Onion & 25 \\
\hline Spice mix & 25 \\
\hline Maida & 30 \\
\hline Slushed ice & 50 \\
\hline
\end{tabular}


Table.2 Physico-chemical and Sensory characteristics of rosemary oil incorporated chicken nuggets

\begin{tabular}{|l|l|l|l|l|}
\hline Quality attributes & Control & $\mathbf{R O} 0.05 \%\left(\mathrm{~T}_{1}\right)$ & $\mathbf{R O} 0.1 \%\left(\mathrm{~T}_{2}\right)$ & $\mathbf{R O} \mathbf{0 . 2 5 \%}\left(\mathrm{T}_{3}\right)$ \\
\hline Emulsion pH & $6.05 \pm 0.04$ & $6.08 \pm 0.05$ & $6.11 \pm 0.04$ & $6.14 \pm 0.04$ \\
\hline Product pH & $6.17 \pm 0.03$ & $6.19 \pm 0.05$ & $6.21 \pm 0.05$ & $6.24 \pm 0.04$ \\
\hline Emulsion Stability (\%) & $94.96 \pm 0.66$ & $95.23 \pm 0.68$ & $95.53 \pm 0.59$ & $95.50 \pm 0.61$ \\
\hline Product yield (\%) & $94.03 \pm 0.61$ & $94.28 \pm 0.65$ & $94.56 \pm 0.59$ & $94.15 \pm 0.43$ \\
\hline Shear force (kg/cm $\left.{ }^{2}\right)$ & $0.49 \pm 0.03$ & $0.49 \pm 0.03$ & $0.48 \pm 0.03$ & $0.47 \pm 0.03$ \\
\hline DPPH in Oil (\%) & - & $8.82^{\mathrm{a}} \pm 0.83$ & $17.33^{\mathrm{b}} \pm 1.67$ & $23.30^{\mathrm{c}} \pm 2.35$ \\
\hline DPPH in Prod (\%) & $20.61^{\mathrm{a}} \pm 1.27$ & $26.00^{\mathrm{b}} \pm 0.91$ & $28.24^{\mathrm{b}} \pm 1.76$ & $29.14^{\mathrm{b}} \pm 2.06$ \\
\hline & \multicolumn{1}{|c|}{ Sensory } & characteristics & & \\
\hline Appearance score & $6.91 \pm 0.11$ & $6.91 \pm 0.12$ & $6.96 \pm 0.12$ & $6.85 \pm 0.11$ \\
\hline Flavour score & $6.15^{\mathrm{a}} \pm 0.19$ & $6.29^{\mathrm{ab}} \pm 0.25$ & $6.79^{\mathrm{b}} \pm 0.12$ & $6.18^{\mathrm{a}} \pm 0.15$ \\
\hline Spiciness score & $6.01^{\mathrm{a}} \pm 0.14$ & $6.11^{\mathrm{a}} \pm 0.14$ & $6.65^{\mathrm{b}} \pm 0.14$ & $6.21^{\mathrm{ab}} \pm 0.21$ \\
\hline Texture score & $7.02 \pm 0.15$ & $7.15 \pm 0.17$ & $7.12 \pm 0.11$ & $6.89 \pm 0.15$ \\
\hline Juiciness score & $6.76 \pm 0.15$ & $6.96 \pm 0.18$ & $6.87 \pm 0.11$ & $6.53 \pm 0.11$ \\
\hline Overall acceptability score & $6.22^{\mathrm{a}} \pm 0.15$ & $6.27^{\mathrm{a}} \pm 0.24$ & $6.90^{\mathrm{b}} \pm 0.07$ & $6.32^{\mathrm{a}} \pm 0.15$ \\
\hline
\end{tabular}

Means bearing different superscripts between columns differ significantly.

This was in accordance with the results of Mielnik et al., (2008) and Naveena et al., (2013) in turkey thighs and chicken patties respectively.

Appearance scores of treated nuggets increased with increase in concentration upto $0.1 \%$ but decreased at $0.25 \%$ concentration. However, the values were not statistically significant.

ANOVA of flavour, spiciness and overall acceptability scores revealed that $\mathrm{T} 2$ nuggets recorded highest numerical values and were statistically significant $(\mathrm{P}<0.05)$ from that of control and other treatments. It was observed that all the flavour of chicken nuggets showed significant differences $(\mathrm{P}<0.05)$ with the control. Flavour scores of treated nuggets showed significant increase $(\mathrm{P}<0.05)$ over the control. It might be due to the phenolic content of RO, which may have contributed to flavor in treated nuggets significantly. Nuggets with $0.1 \%$ RM oil (T2) recorded highest flavor, spiciness and overall acceptability. Ntzimani et al., (2010) found that addition of $0.20 \%$ rosemary oil in semi cooked coated chicken fillets produced a distinct but agreeable pleasant odor and taste, which was well accepted by the sensory evaluation panelists and Jridi et al., 2015 recorded increased flavour scores and overall acceptability in turkey sausages incorporated with Rosemary essential oil at 500 ppm.

Texture scores increased numerically in treated samples upto $0.1 \%$ and then decreased at $0.25 \%$. Juiciness scores of treated samples decreased linearly in treated nuggets with increase in concentration of rosemary oil. However, no statistical difference was observed for texture and juiciness scores between treated and control nuggets, which was in concurrent with the results of Mendiratta et al., 2013 and Kalaikannan, 2014 in chicken nuggets and chicken patties repectively.

The results of this study showed that DPPH scavenging activity of rosemary essential 
increased with increasing concentration of essential oil, which showed higher antioxidant property. But at higher concentration of rosemary essential oil incorporated chicken are not organoleptically acceptable. Hence, adding rosemary essential oil at $0.10 \%$ gives better antioxidant property and organoleptically acceptable.

\section{References}

Balentine, C.W., P.G. Cranaall and C.A. O'Bryan, 2006. The pre and postgrinding application of rosemary and its effect of lipid oxidation and colour during storage of ground beef. Meat Sci., 73 413-421.

Baliga, B. R., and N. Madaiah, 1971. Preparation of mutton sausages. J. Food Sci., 36(4): 607-610.

Berry, B.W. and Stiffler, D.M. 1981. Effects of electrical stimulation, boning temperature, formulation and rate of freezing on sensory, cooking, chemical and physical properties of ground beef patties. J. Food Sci. 46: 1103-1106.

Burt, S. A. 2004. Essential oils: Their antibacterial properties and potential applications in foods: A review. Inter. $J$ Food Microbio., 94: 223-253.

Casaburi, A., A. Nasi., I. Ferrcino, R.D. Monaco and D. Ercolini, 2011. Spoilage related activity of Carnobbacterium maltaromaticum strains in air stored and vaccum packaged meat..Appl. Environ. Microbio., 77: 7382-7383.

Darwish, S. M., M. A. El-Geddawy, R. M. Khalifa and R. A. Mohamed, 2012. Physico-chemical changes of frozen chicken burger formulated with some spices and herbs. Front. Sci., 2(6): 192199.

FAOSTAT 2013. FAO Statistics Division 2013. www.faostat.org

Fernandez-Lopez, J., N. Zhi, L. AlesonCarbonell, J. A. Perez-Alvarez and V.
Kuri, 2005. Antioxidant and antibacterial activities of natural extracts: application in beef meatballs. Meat Sci., 69(3): 371-380.

Frankel, E.N., S.W. Huang, R. Aeschbach and E. Prior, 1996. Antioxidant activity of a rosemary extract and its constituents, carnosic acid, carnosol and rosmarinic acid, in bulk oil and oil- in - water emulsion. J. Agri. Food Chem. 44 (1): 131-135.

Hammer, K.A., C.F. Carson and T.V. Riley, 1999. Antimicrobial activity of essential oils and other plant extracts. J.Appl. Microbiol. 86: 985-990.

Huber, W., W. Vogan and Y. Le Minter, (2002). Carrot fibre as opportunity Natural carrot fibre can be used for dietary fibre enrichment, water binding and as fat substitute in sausages. Fleischwirtschaft International, 4: 1315.

Hussian, A.I., F. Anwar and S.A.S. Chatha, (2010). Rosmarinus officinalis essential oil: antiproliferative, antioxidant and antibacterial activities. Braz.J. Microbiol., 41: 1070-1078.

Jridi, M., R. Siala, N. Fakhfakh, M.A. Ayadi, M. Elhatmi, M.A. Taktak, M. Nasri and N. Zouari, 2015. Effect of rosemary leaves and essential oil on turkey sausage quality. Acta alimentaria., 44(4): 534-541.

Kalaikannan, A. 2014. Exnsion of shelf life of chicken meat patties using natural preservatives by application of hurdle technology. Doctoral thesis submitted to Tamil Nadu Veterinary and Animal Sciences University, Chennai.

Kanimozhi, R. K., 2012. Studies on incorporation of selected vegetables and herbs on the quality of chicken nuggets. Ph.D. thesis submitted to the Deemed University, IVRI, Izatnagar, Bareilly, U.P., India. 
Keeton, J. T. 1983. Effects of fat and $\mathrm{NaCl} /$ phosphate levels on the chemical and sensory properties of pork patties. J.Food Sci., 48(3): 878-881.

Lawrie, R.A.1998. The eating quality of meat. In: Lawrie R.A. (ed.), Meat Science, Cambridge, England: Woodhead Publishing Ltd, 212-257.

Mendiratta, S.K., A.T. Shinde and B.G. Mane. 2013. Effect of added vegetable (carrot, radish and capsicum) as functional ingredients in mutton nuggets. J.Meat Sci.Tech., 1(2): 71-76.

Mielnik, M. B., S. Sem, B. Egelandsdal and G. Skrede, 2008. By-products from herbs essential oil production as ingredient in marinade for turkey thighs. LWT-Food Sci. Technol., 41(1): 93-100.

Naveena, B. M., A. R. Sen, S. Vaithiyanathan, Y. Babji and N. Kondaiah, 2008. Comparative efficacy of pomegranate juice, pomegranate juice, pomegranate rindpowder extract and BHT as antioxidants in cooked chicken patties. Meat Sci, 80(2): 1304 1308.

Naveena, B. M., S. Vaithiyanathan, M. Muthukumar, A. R. Sen, Y. P. Kumar, M. Kiran and K. R. Chandran, 2013. Relationship between the solubility, dosage and antioxidant capacity of carnosic acid in raw and cooked ground buffalo meat patties and chicken patties. Meat science, 95(2): 195-202.

Ntzimani, A. G., V. I. Giatrakou and I. N. Savvaidis, 2010. Combined natural antimicrobial treatments (EDTA, lysozyme, rosemary and oregano oil) on semi cooked coated chicken meat stored in vacuum packages at $4 \mathrm{C}$ : microbiological and sensory evaluation. Innov.Food Sci. Emerg. Technol., 11(1): 187-196.

Seydim, A.C., and G. Sarikus, 2006. Antimicrobial activity of whey protein baesd edible films incorporated with oregano, rosemary and garlic essential oils. Food Res Int., 39: 639- 644.

Snedecor, G. W. and W.G. Cochran, (1994). Statistical Methods ( $8^{\text {th }}$ ed.). New Delhi: Oxford and IBH Pub.Co.

Trout, E.S., M.C. Hunt, D. E. Johnson, J.R. Claus, C.L. Kastner, and D.H. Kropf, 1992. Characteristics of low-fat ground beef containing texture modifying ingredients. J.Food Sci., 57(1): 19-24.

Wu, H. C., H. M. Chen and C. Y. Shiau, 2003. Free amino acids and peptides as related to antioxidant properties in protein hydrolysates of mackerel (Scomber austriasicus).Food Res. Int., 36: 949-957.

\section{How to cite this article:}

Sutha, M., R. Selvaraj, V.V. Kulkarni, V. Chandirasekaran, S.C. Edwin and Malmarugan, S. 2018. Effect of Rosemary Essential Oil on the Quality Characteristics of Chicken Nuggets. Int.J.Curr.Microbiol.App.Sci. 7(08): 4686-4693. doi: https://doi.org/10.20546/ijcmas.2018.708.492 